\title{
Effect of Response and Knowledge about Back-Referral Program toward Patient's Obedience at the Fatmawati National Vertical Hospital
}

\section{Astia Dwiputri Lestari, Wahyu Sulistiadi, Rakhmawati Caesaria, and Fadlia Murtafia}

Department of Health Administration and Policy, Faculty of Public Health, Universitas Indonesia, Depok, Indonesia

\section{Abstract}

Back-referral program in the era of social health insurance has become one of the leading programs to improve the health service quality for social health insurance participant. However, the effectiveness of the implementation of this program is not yet optimal. This study aimed to determine the depth influence patient response and

Corresponding Author: Astia Dwiputri Lestari astiadwiputrilestari@gmail.com

Received: 26 December 2018 Accepted: 23 February 2019 Published: 7 March 2019

Publishing services provided by Knowledge E

(c) Astia Dwiputri Lestari et al. This article is distributed under the terms of the Creative Commons Attribution License, which permits unrestricted use and redistribution provided that the original author and source are credited.

Selection and Peer-review under the responsibility of the $2 \mathrm{nd}$ International Meeting of Public Health 2016 Conference Committee. knowledge social health insurance patient toward a back-referral program at The Fatmawati National Vertical Hospital. This study was conducted at The Fatmawati National Vertical Hospital in September 2016. This study was a quantitative study with sample of 202 outpatients' social health insurance with chronic disease. Data were collected by using primary data with questionnaire as a research instrument. Results found that odd ratio value between patient knowledge, responsiveness hospital workers and access to hospital was 15.3 (95\% Cl=3.6-65.4, p-value 0.001), which meant that patients who had an excellent understanding would follow back referral program 15.3 times higher than who had less knowledge and respondents which stated that the good of responsiveness hospital would follow back-referral plan 7.6 times higher than patients who reported bad responsiveness hospital workers, after controlled by knowledge and access variables. Social health insurance patient behavior in the back-referral program at The Fatmawati National Vertical Hospital was influenced by patient knowledge and responsiveness of hospital worker.

Keywords: Back-referral plan; social health insurance; hospital; chronic disease

\section{Introduction}

A referral can be defined as a process in which a health worker at a one level of the health system, having insufficient resources (drugs, equipment, skills) to manage a clinical condition, seeks the assistance of a better or differently resourced facility at the same or higher level to assist in, or take over the management of, the client's case. When the 
is essential. Service of the back-referral program is health service provided for patients with the stable chronic disease still needing treatment or long-term nursing care held in primary health care on the recommendation/reference from the hospital doctor (World Health Organization (WHO) 2013). There are so many advantages for patients if they follow the back-referral program, i.e., improving access to health services, improving health services that include access to promote, preventive, curative and rehabilitative, and developing the doctor-patient relationship in the context of holistic services, simplify drugs collection. The back-referral program aims to reduce the number of hospital patients at the secondary or even tertiary healthcare (Badan Penyelenggara Jaminan Sosial (BPJS) 2014).

Back-referral program in the era of social health insurance has become one of the leading programs to improve the health service quality for social health insurance participant. Beside to facilitate access to services patient with chronic disease, this program makes management disease of social health insurance participant more effective, because when the patient has declared recovered by hospital doctors, the treatment continues at primary health care. This program allows patients to have surgery closer from home and shorten the treatment time (BPJS 2014). Back-referral mechanism begins with a letter of recommendation hospital doctor about the patient's condition. Furthermore, patients will receive treatment and redeem drugs at primary health care (WHO 2013). However, the effectiveness of the implementation of this program is not yet optimal. Both at national and regional hospitals, patients with chronic diseases are not yet fully referred back. This study aimed to determine the depth influence patient response and knowledge social health insurance patient toward a back-referral program at The Fatmawati National Vertical Hospital.

\section{Methods}

A cross-sectional study was carried out in the city of Jakarta, located in The Fatmawati National Vertical Hospital. The study population was social health insurance participants seeking treatment in The Fatmawati National Vertical Hospital on September 2016. To be included in the study, the patient had to be outpatient, had a chronic disease (such as hypertension, diabetes, etc.) and accompanied by a guardian (if patient too old to answers the questionnaire). Random sampling was adopted for the randomization. The number of samples was obtained from the multiplication of total variables (10 variables) with ten then added 1 and multiplied by 2 (calculation for minimum example). And for this study, there were 202 samples obtained. 
There were nine variables examined in this study: patient's obedience, hospital facilities, the reliability of hospital workers, the responsiveness of hospital workers, patient assurance, accessibility, patient knowledge, doctor instruction, and positive attitude.

Design of this study was cross-sectional. Data were collected with questionnaire as a research instrument. Data collection was performed after the patient had been treated. Patients who met the inclusion criteria were asked to answer the survey. If patients had a difficulty in filling the survey, the patient's guardian could help to fill the questionnaire. A pilot study was conducted with a sample of 30 patients to test the validity and reliability of the survey.

\section{Results}

Thirty-two questions were divided into four main variables and ten main sub-variables. The four main variables were patient's obedience toward the back-referral program, predisposition factor, enabling factor, and reinforcing element. The variable of patient's compliance toward back-referral program was whether patients follow the back-referral plan or not. The result was $95 \%$ patients said they did not develop the back-referral program and only $5 \%$ supported the back-referral program.

Predisposition factor found that $\mathbf{7 2 . 3 \%}$ had a positive attitude and $27.7 \%$ remaining had an adverse reaction. Meanwhile, $94.1 \%$ most patients had poor knowledge about the back-referral program, and only $5.9 \%$ had a good understanding of the back-referral program. The result showed that although many patients had imperfect knowledge, they had a positive attitude about the back-referral program.

Based on the enabling factor, $95 \%$ of patients said that hospital facilities were adequate and $5 \%$ said that hospital facilities were inadequate. Meanwhile, seen from patient access to the hospital, the majority of patients reported having easy access, as many as $93.1 \%$ and only $6.9 \%$ said had complicated access to the hospital. The results from patient assurance showed that $73.3 \%$ of patients had high confidence and $26.7 \%$ of patients confess they had a low certainty. Another submarine variable, the reliability of hospital workers, showed high loyalty of hospital workers and the remaining, which was just $14.9 \%$, said that hospital worker had low reliability. The results for responsiveness of hospital workers showed that most patients stated that hospital workers had high responsiveness and only $5.9 \%$ claimed that low reactivity of hospital workers. It could be seen by enabling factor; most patients gave a positive assessment. For reinforcing element, $92.1 \%$ of patients said that hospital workers had a high empathy and only $7.9 \%$ of patients who think that hospital workers had a profound insight. 
TABLE 1: Univariate Analysis Results from Each Variable.

\begin{tabular}{|c|c|c|}
\hline \multirow{2}{*}{ Variables } & \multicolumn{2}{|c|}{ Frequency $(n=202)$} \\
\hline & $\mathbf{n}$ & $\%$ \\
\hline \multicolumn{3}{|c|}{ Back-Referral Obedience } \\
\hline Not Following & 192 & 95.0 \\
\hline Following & 10 & 5.0 \\
\hline \multicolumn{3}{|c|}{ Patient's Behavior } \\
\hline Positive & 10 & 5 \\
\hline Negative & 192 & 95 \\
\hline \multicolumn{3}{|c|}{ Patient's Knowledge } \\
\hline Bad & 19 & 94.1 \\
\hline Good & 12 & 5.9 \\
\hline \multicolumn{3}{|c|}{ Hospital Facilities } \\
\hline Inadequate & 10 & 5 \\
\hline Adequate & 192 & 95 \\
\hline \multicolumn{3}{|c|}{ Patient's Accessibility to Hospital } \\
\hline Difficult & 14 & 6.9 \\
\hline Easy & 188 & 93.1 \\
\hline Total & 202 & 100.0 \\
\hline \multicolumn{3}{|c|}{ Patient's Assurance } \\
\hline Low & 54 & 26.7 \\
\hline High & 148 & 73.3 \\
\hline \multicolumn{3}{|c|}{ Reliability of Hospital Workers } \\
\hline Low & 30 & 14.9 \\
\hline High & 172 & 85.1 \\
\hline \multicolumn{3}{|c|}{ Responsiveness of Hospital Workers } \\
\hline Bad & 12 & 5.9 \\
\hline Good & 190 & 94.1 \\
\hline \multicolumn{3}{|c|}{ Empathy of Hospital Workers } \\
\hline Low Hight & 16 & 7.9 \\
\hline Easy & 185 & 92.1 \\
\hline Total & 202 & 100.0 \\
\hline
\end{tabular}

The results for bivariate analysis between predisposition factor and patient's obedience toward back-referral program were presented on Table 3. From patient knowledge, it could be seen that the most significant proportion of patients who had been following back-referral plan were patients who have good experience $(p<0.05)$, thus there was a substantial difference between the portion of patient's obedience in patients who had good knowledge and patients who had less knowledge about the back-referral program. 
TABLE 2: Bivariate Analysis Results From Each Variable.

\begin{tabular}{|c|c|c|c|c|c|c|c|c|}
\hline \multirow[t]{3}{*}{ Variables } & \multicolumn{6}{|c|}{ Obedience Back-Referral Program } & \multirow[t]{3}{*}{$p$ value } & \multirow{3}{*}{$\begin{array}{l}\text { Odd Ratio } \\
\text { (95\% Cl) }\end{array}$} \\
\hline & \multicolumn{2}{|c|}{ Not Following } & \multicolumn{2}{|c|}{ Following } & \multicolumn{2}{|c|}{ Total } & & \\
\hline & $\mathbf{N}$ & $\%$ & $\mathbf{N}$ & $\%$ & $\mathbf{N}$ & $\%$ & & \\
\hline \multicolumn{9}{|c|}{ Patient's Behavior } \\
\hline Positive & 54 & 96.4 & 2 & 3.6 & 56 & 100.0 & 0.73 & $\begin{array}{c}1.57 \\
(0.32-7.61)\end{array}$ \\
\hline Negative & 138 & 94.5 & 8 & 5.5 & 146 & 100.0 & & \\
\hline \multicolumn{9}{|c|}{ Patient's Knowledge } \\
\hline Bad & 184 & 96.8 & 6 & 3.2 & 190 & 100.0 & 0.001 & $\begin{array}{c}15.3 \\
(3.6-65.4)\end{array}$ \\
\hline Good & 8 & 66.7 & 4 & 33.3 & 12 & 100.0 & & \\
\hline \multicolumn{9}{|c|}{ Hospital Facilities } \\
\hline Inadequate & 10 & 100 & 0 & 0 & 10 & 100.0 & 1.0 & \\
\hline Adequate & 182 & 94.8 & 10 & 5.2 & 192 & 100.0 & & \\
\hline \multicolumn{9}{|c|}{ Patient's Accessibility to Hospital } \\
\hline Difficult & 14 & 87.5 & 2 & 12.5 & 16 & 100.0 & 0.182 & $\begin{array}{c}0.32 \\
(0.06-1.63)\end{array}$ \\
\hline Easy & 178 & 95.7 & 8 & 4.3 & 186 & 100.0 & & \\
\hline \multicolumn{9}{|c|}{ Patient's Assurance } \\
\hline Low & 52 & 96.3 & 2 & 3.7 & 54 & 100.0 & 1.0 & $1.5(0.3-7.3)$ \\
\hline High & 140 & 94.6 & 8 & 5.4 & 148 & 100.0 & & \\
\hline \multicolumn{9}{|c|}{ Reliability of Hospital Workers } \\
\hline Low & 28 & 93.3 & 2 & 6.7 & 30 & 100.0 & 0.646 & $\begin{array}{c}0.68 \\
(0.14-3.4)\end{array}$ \\
\hline High & 164 & 95.3 & 8 & 4.7 & 172 & 100.0 & & \\
\hline \multicolumn{9}{|c|}{ Responsiveness of Hospital Workers } \\
\hline Bad & 10 & 83.3 & 2 & 16.7 & 12 & 100,0 & 0.112 & $\begin{array}{c}0.22 \\
(0.04-1.17)\end{array}$ \\
\hline Good & 182 & 95.8 & 8 & 4.2 & 190 & 100.0 & & \\
\hline \multicolumn{9}{|c|}{ Empathy of Hospital Workers } \\
\hline Low High & 16 & 100 & 0 & 0 & 16 & 100.0 & 1.0 & \\
\hline Easy & 176 & 94.6 & 10 & 5.4 & 186 & 100.0 & & \\
\hline
\end{tabular}

Results of statistical tests also showed that the odds ratio $(\mathrm{OR})$ was $15.3(95 \% \mathrm{Cl}=3.6$ 65.4), showing that patients who had an excellent knowledge were 15.3 times more likely to follow the back-referral program compared to patients who had less experience.

To decide the determinant factor of patient's obedience toward the back-referral program, researchers used multivariate statistical analysis. From Table 3, it could be seen the odd ratio and $p$ value for each variable. Variables that had $p$ value less than 0.25 would include in the multivariate analysis. The results were accessibility to the hospital, responsiveness of hospital workers and patient knowledge. Based on the study and 
multivariate modeling, it was obtained a final model with independent variables: patient knowledge and responsiveness of hospital workers. The odds ratio of respondents who had an excellent understanding was 0.03 times to follow the back-referral program compared with respondents who had less knowledge after controlled by the responsiveness of hospital workers and accessibility to hospital variable. As for the odds ratio of respondents, it was stated that the high responsiveness hospital workers would be 7.6 times higher to follow the back-referral program compared with respondents reporting low responsiveness hospital workers after controlled patient knowledge and accessibility to hospital variable. Multivariate analysis also found that the variable that most affected the patient's obedience back-referral program was the responsiveness hospital workers.

\section{Discussion}

This study attempted to assess the depth influence of patient's response and knowledge of social health insurance patient toward a back-referral program at The Fatmawati National Vertical Hospital. It examined the influence of back-referral program to social health insurance patient, how much they knew about the back-referral program, the impact of hospital's factor and patient' factor that made patient disobey the back-referral program.

Referral policy, which is an essential part of any nation's health system, is facing a lot of problems especially in developing countries leading to overcrowding in the hospitals (Abondurin 2013). The data described that majority of respondents said that they did not follow the back-referral program. This result was identical with the study of Abraham et al. which described that only a small number of patients referred to primary health care (Abraham et al. 2015).

This study showed that social health insurance patient's behavior in the back-referral program at The Fatmawati National Vertical Hospital was influenced by patient's knowledge and hospital worker's responsiveness. Experience is a fundamental aspect of determining a person's behavior to be aware or not, as well as to regulate their behavior.

Education becomes the basis of action (Notoatmodjo 2003). If a patient had limited knowledge about some program, they would not obey the program. Patients do not have any idea about the program, benefits and their loses if they follow the plan. So, the solution for this problem is to socialize back-referral program to social, national health insurance patient. Patients should explain what the benefits they will gain if they follow and obey this program. Therefore, patients are expected to increase their knowledge about the program and will affect their behavior to obey the back-referral program. 
Besides the patient's knowledge, the result showed that responsiveness of hospital worker influence patient's obedience toward the back-referral program. This hospital worker's responsiveness was described by how hospital managed their worker to service the patients. The result showed that the patient gave a functional assessment for The Fatmawati National Vertical Hospital's responsiveness. Started from patient registration to patient treatment, the patient agreed that The Fatmawati National Vertical Hospital's service was quick and precise. Reactivity included in patient satisfaction and quality of care, but it's a distinct entity that refers to the way individuals treated and the environment in which they managed when seeking health care (WHO 2000; Figueras 2004; Saltman 2004; Mohammed 2013). A responsive health insurance scheme ensures that users can obtain healthcare in a client-oriented manner with no discrimination of different population groups (WHO 2000; Carrin 2004; Carrin 2005).

From this study, we assumed that back-referral program has not been functioning effectively from both primary health care side and social health insurance side. For primary health care, the solution is to strengthen primary health care because it is essential to improve access and quality of health care especially in low/middle income countries (Lerberghe 2008). Implementing effective interventions to strengthen primary concern has been challenging, and many efforts have limited success because of insufficient financial resources, weak political engagement, or inadequate management of the referral patterns of patients using primary health centers and secondary hospitals. A key element of primary health care is its referral system in which patients can access care at community-based health posts or health centers before accessing higher-levels of concern such as secondary and tertiary hospitals. Other studies also have found that such increased use of primary care facilities is a cost-effective investment and can improve health outcomes (Bradley et al. 2011; Gebrehiwot et al. 2012; Curry et al. 2013).

And for social health insurance organization, the solution is to increase public awareness for the back-referral program. The is similar with Abraham' study, stating that general knowledge for a referral or back-referral system must be improved, such as providing education through the media while making an effort to equip the peripheral health facilities with drugs, equipment, and personnel to enhance their credibility (Abraham et al. 2015).

\section{Conclusion}

In summary, this study described social health insurance patient behavior in the backreferral program at The Fatmawati National Vertical Hospital influenced by patient knowledge and responsiveness of hospital worker. Providing back-referral program 
education through the media while making an effort to equip the primary health care facilities with drugs, equipment, and personnel to improve the primary health care, will solve the problem of inefficiency back-referral program.

\section{Acknowledgment}

This research was supported by International Publication Indexed for Thesis Grants from the University of Indonesia.

\section{References}

[1] Abondurin, et al. 2013. Awareness and perception toward referral in health care: A study of adult residents in I/orin, Nigeria. Retrieved from http://remote-lib.ui.ac.id: 2073/docview/849642789/BD1B9D8B901C4E09PQ/1?accountid=17242

[2] Abraham O., E. Linnander, H. Mohammed, E. Bradley, et al. 2015. A Patient-Centered Understanding of the Referral System in Ethiopian Primary Health Care Units. PLoS One 10 (10): e0139024

[3] Badan Penyelenggara Jaminan Sosial (BPJS). 2014. Rujuk Balik di Era JKN. Retrieved from http://www.bpjs-kesehatan.go.id/bpjs/index.php/post/read/2014/261/RujukBalik-di-Era-JKN/berita

[4] Bradley E., J.W. Thompson, P. Byam, T.R Webster, et al. 2011. Access and quality of rural healthcare: Ethiopian Millennium Rural Initiative. International Journal for Quality in Health Care 23(3):222-30.

[5] Carrin G, C. James. 2004. Reaching universal coverage via social health insurance: key design features in the transition period. WHO Discussion paper 2. Geneva, Switzerland: World Health Organization.

[6] Carrin G, C. James. 2005. Key Performance Indicators for the Implementation of Social Health Insurance. Appl Health Econ Health Policy 4: 15. doi:10.2165/00148365200504010-00004.

[7] Curry, et al. 2013. Evaluation of the Ethiopian Millennium Rural Initiative: Impact on Mortality and Cost-Effectiveness.

[8] Figueras et al. 2004. Patterns and performance in social health insurance systems. In Social health insurance systems in western Europe. New York: Open University.

[9] Gebrehiwot T., I. Goicolea, K. Edin, M.S. Sebastian. 2012. Making logical choices: women's experiences of delivery care in Northern Ethiopia. BMC pregnancy and childbirth 12: 113. DOI: 10.1186/1471-2393-12-113 
[10] Lerberghe, Van W. 2008. The World Health Report: Primary Health Care: Now More Than Ever. World Health Organization.

[11] Mohammed, S., J.L. Bermejo, A. Soares, R. Sauerborn, H. Dong. 2013. Assessing the responsiveness of health care services within a health insurance scheme in Nigeria: users' perspectives. BMC Health Services Research 13: 502. DOI: 10.1186/1472-696313-502.

[12] Notoatmodjo, S. 2003. Pendidikan dan Perilaku Kesehatan. Jakarta: Rineka Cipta

[13] Saltman R.B., R. Busse, J. Figueras. 2004. Social health insurance systems in Western Europe. Berkshire, New York: Open University Press.

[14] World Health Organization (WHO). 2000. World health report: health systems are improving performance. Geneva: World Health Organization.

[15] World Health Organization (WHO). 2013. Referral Systems - A Summary of Key Processes to Guide Health Services Managers. Retrieved from http://www.who.int/ management/facility/referral/en/index.html. 